\title{
A Systematic Review and Pooled Analysis of CPR-Associated Cardiovascular and Thoracic Injuries
}

\author{
Andrew C. Miller, MD¹, Shannon F. Rosati, MD², Anthony F. Suffredini, MD¹, and David S. \\ Schrump, MD ${ }^{2}$ \\ ${ }^{1}$ Critical Care Medicine Department, Clinical Center, National Institutes of Health, Bethesda, MD \\ ${ }^{2}$ Surgery Branch, Thoracic Oncology Section, National Cancer Institute, National Institutes of \\ Health, Bethesda, MD
}

\begin{abstract}
OBJECTIVE-The incidence of thoracic injuries resulting from cardiopulmonary resuscitation (CPR) is not well characterized. We describe a case in which a CPR-associated atrial rupture was identified with ultrasound and successfully managed in the intensive care unit with a bedside thoracotomy and atrial repair. We then describe a systematic review with pooled data analysis of CPR-associated cardiovascular, pulmonary, pleural, and thoracic wall injuries.
\end{abstract}

DATA SOURCES-PubMed, Scopus, EMBASE, and Web of Science were searched to identify relevant published studies. Unpublished studies were identified by searching the Australian and New Zealand Clinical Trials Registry, World Health Organization International Clinical Trials Registry Platform, Cochrane Library, ClinicalTrials.gov, Current Controlled Trials, and Google.

STUDY SELECTION-Inclusion criteria for the pooled analysis were any clinical or autopsy study in which a) patients underwent cardiopulmonary resuscitation, b) chest compressions were administered either manually or with the assistance of active compression-decompression devices, and c) autopsy or dedicated imaging assessments were conducted to identify complications. Exclusion criteria for the pooled analysis were pre-clinical studies, case reports and abstracts.

DATA EXTRACTION-Nine-hundred twenty-eight potentially relevant references were identified. Twenty-seven references met inclusion criteria.

DATA SYNTHESIS-A systematic review of the literature is provided with pooled data analysis.

\footnotetext{
Corresponding Author: Andrew C. Miller M.D., Critical Care Medicine Department, Clinical Center, Bldg 10, Rm. 2C-145, 10 Center Drive, National Institutes of Health, Bethesda, MD. 20892-1662, Andrew.Miller3@nih.gov; Taqwa1@ gmail.com, Tel: 301-496-9320. Fax: 301-402-1213.

Publisher's Disclaimer: This is a PDF file of an unedited manuscript that has been accepted for publication. As a service to our customers we are providing this early version of the manuscript. The manuscript will undergo copyediting, typesetting, and review of the resulting proof before it is published in its final citable form. Please note that during the production process errors may be discovered which could affect the content, and all legal disclaimers that apply to the journal pertain.

AUTHOR CONTRIBUTIONS: Drs. Miller, Rosati, Suffredini, and Schrump contributed to all stages of patient care. Drs. Miller and Suffredini researched and wrote the manuscript. Drs. Miller, Suffredini, and Schrump were involved in manuscript editing and revision.

DISCLOSURE: The authors have no conflicts of interest to disclose.
} 
CONCLUSIONS-The incidence of reported CPR-associated cardiovascular and thoracic wall injuries varies widely. CPR with active compression-decompression devices has a higher reported incidence of cardiopulmonary injuries. Bedside ultrasound may be a useful adjunct to assess and risk-stratify patients to identify serious or life-threatening CPR-associated injuries.

\section{Keywords}

CPR; cardiopulmonary resuscitation; automated compression devices; vascular injury; cardiac injury; thoracic injury

\section{INTRODUCTION}

Effective chest compression remains the cornerstone of successful cardiopulmonary resuscitation (CPR). International guidelines note the critical importance of the quality of manual chest compression components including hand position, rescuer and victim position, and the depth and rate of compression and decompression. ${ }^{1,2}$ In attempts to improve outcomes with CPR, several devices have been developed to improve the consistency and quality of chest compression and CPR. While none of these circulatory adjuncts are currently recommended because of insufficient data, some are being used routinely in resuscitation as alternatives to standard manual chest compressions. ${ }^{3,4}$ These include active compression-decompression (ACD) devices based on suction-cup technology and automated devices using either piston technology or a load-distributing band.

The incidence of CPR-associated thoracic injuries in the setting of manual chest compressions or with circulatory adjuncts using active compression-decompression technology is not well characterized. Injuries to the thoracic wall, pulmonary and cardiovascular systems may cause significant morbidity and mortality and may represent potentially reversible causes of resuscitation failure. We describe a case in which an atrial rupture associated with standard manual CPR was identified with ultrasound and successfully managed in the intensive care unit with a bedside thoracotomy and atrial repair. This case was the impetus for us to perform a systematic review with pooled data analysis of CPR-associated cardiovascular, pulmonary, pleural, and thoracic wall injuries.

\section{CASE}

A 44-year-old woman with a 16-year history of synovial cell sarcoma and a recent asymptomatic pulmonary embolism underwent a right thoracotomy with parietal pleurectomy, extra-pericardial resection of a large inferior mediastinal mass extending from the carina to the diaphragmatic hiatus, and excision of several right pulmonary metastases by parenchyma sparing techniques. The patient's sarcoma had originated in the right thigh, and had been definitively treated with surgery and adjuvant radiation without local recurrence. She subsequently developed isolated metachronous right pulmonary metastases, which were treated by resection, each time rendering her with no evidence of disease. On routine imagining approximately six months prior to her most recent surgery, she was noted to have a large mass in the inferior mediastinum with several pulmonary nodules ranging in size from $1-3 \mathrm{~cm}$ in diameter. Due to the volumes and locations of disease, she underwent Adriamycin and ifosphamide therapy with partial response, and was referred to the NCI for 
resection of residual disease. Heparin-based therapy was briefly interrupted, and enoxaparin was re-started on post-operative day 2 . On post-operative day 12 , she developed an acute alteration in mental status followed by hypotension and hypoxemia that progressed to cardiac arrest with pulseless electrical activity (PEA) (time 0). Advanced cardiac life support was initiated and reversible causes of PEA evaluated. A bedside transthoracic echocardiogram revealed a dilated right atrium and ventricle with no wall motion and no pericardial effusion. Return of spontaneous circulation (ROSC) occurred and a massive pulmonary embolism was considered to be the most likely cause of the cardiac arrest. At 18 minutes she again developed PEA and was treated with $100 \mathrm{mg}$ (IV) of tissue plasminogen activator. Within minutes, ROSC occurred and supportive care continued. Bleeding began from her pre-existing thoracotomy tubes and progressed to hemorrhagic shock with 8 liters of blood loss after $135 \mathrm{~min}$. Despite aggressive volume and vasopressor therapy, she remained pre-load dependent with a narrow pulse pressure. A repeat transthoracic echocardiogram at 205 minutes demonstrated the new development of an intrapericardial echodense mass that completely compressed the right ventricle throughout the cardiac cycle (Figure 1). At 230 minutes the patient again developed PEA that deteriorated to asystole by 243 minutes. Uninterrupted CPR was continued and a bedside thoracotomy was performed with release and evacuation of intrapericardial clot under tension. The patient experienced persistent hemorrhage from an identified right atrial tear that was closed. Intrathoracic cardiac massage was performed, and resuscitation continued with ROSC. Surgical closure was performed at 335 minutes. The patient recovered without significant neurological sequelae.

\section{METHODS}

A systematic search was performed to capture published and unpublished pre-clinical and clinical studies of CPR-associated cardiac, vascular and thoracic injuries. PubMed, Scopus, EMBASE, and Web of Science were searched to identify relevant published studies. The search strategies were adapted to accommodate the unique searching features of each database, including database-specific MESH and EMTREE controlled vocabulary terms. Searches were not limited by date, language or publication status. (Detailed search strategies are summarized in Appendix 1). The cited and citing references of selected studies were also searched for additional relevant material. To minimize publication bias, relevant unpublished studies were identified by searching the Australian and New Zealand Clinical Trials Registry, World Health Organization International Clinical Trials Registry Platform, Cochrane Library, ClinicalTrials.gov, Current Controlled Trials, and Google.

Inclusion criteria were any clinical or autopsy study in which a) patients underwent cardiopulmonary resuscitation, b) chest compressions were administered either manually (standard) or with the assistance of active compression-decompression devices, and c) assessments were made to specifically identify CPR-associated cardiopulmonary complications either by autopsy or dedicated imaging. Exclusion criteria for the pooled analysis were pre-clinical studies, and case reports. Clinical and methodological diversity precluded combining these studies in a meta-analysis. 


\section{RESULTS and DISCUSSION}

Our search strategy identified 928 potentially relevant studies. Additional references were identified from bibliography assessments. Twenty-seven references met inclusion criteria. For resuscitation non-survivors, injuries were detected post-mortem by autopsy assessments. For resuscitation survivors, injuries were detected by plain radiographs, CT scan, ultrasound assessment, or combinations of these modalities. The data from the pooled analysis is summarized in Tables $1-4$.

The reported cardiovascular and thoracic injuries associated with CPR vary widely. Several reports describe high rates of injury depending on whether patients are treated with standard CPR (32-45\%), active compression decompression (ACD) CPR (58-75\%), or standard CPR followed by ACD-CPR (up to $100 \%$ ). ${ }^{5-11}$ Up to $11 \%$ of patients may have multiple CPRassociated injuries ${ }^{5}$ and major injuries occur in up to $3 \%$ and $7 \%$ of CPR-treated pediatric and adult patients respectively. ${ }^{5-9}$

\section{CARDIAC AND VASCULAR INJURIES}

Major cardiac and large vessel injuries may occur following standard CPR (Figure 2). Cardiac and pericardial injury may occur in the absence of associated thoracic wall injury. ${ }^{12,13}$ In a pooled analysis, pericardial injury occurs in $8.9 \%$ and hemopericardium occurs in $7.5 \%$ of CPR-treated patients (Table 1) following standard or ACDCPR. $.5,6,8,11,13-22$ Resultant cardiac tamponade has been described as well ${ }^{17,23-26}$ either with or without associated pericardial laceration.

A broad spectrum of cardiac injuries have been observed including both contusions of the epi-, myo-, or endocardium $(4.4 \%, 1.7 \% \text {, and } 3 \% \text { respectively })^{5-7,9-11,18,26-31}$ and lacerations or chamber ruptures $(0.6 \%)$ involving the right atrium, ${ }^{13}, 15,23,24$ right ventricle, ${ }^{13,28,32-34}$ left ventricle, ${ }^{5,12,18,25,28}$ or locations not specified. ${ }^{5,14,17}$ Cardiac rupture has been associated with thoracic wall injuries or myocardium weakened by ischemia. However, there are cases in which cardiac rupture has been observed independent of these conditions. ${ }^{12,13}$ Similar to the case described above, right atrial and ventricular rupture following closed-chest standard CPR associated with pulmonary embolism has occurred in the absence of chest wall injury. ${ }^{13}$ It is exceedingly unlikely that the cardiac rupture observed in our case was directly related to the patient's recent surgery since the mediastinal mass was resected in an extra-pericardial manner without technical complications. When rapidly identified, such injuries may be successfully managed with thoracotomy and cardiac repair. ${ }^{12}$ Other significant cardiac complications of CPR including intracavitary hematoma, ${ }^{35}$ prosthetic valve dehiscence, ${ }^{30}$ papillary muscle rupture, ${ }^{36}$ and conductions system injuries that occurred in up to $10 \%$ of patients in one report. ${ }^{37}$

Major vascular complications (Table 2) including aneurysm, pseudoaneurysm, dissection, laceration or rupture to the coronary vasculature, ${ }^{37-42}$ coronary bypass grafts, ${ }^{43}$ aorta, $8,10,11,17,32,44-47$ subclavian artery and vein, and the vena cava ${ }^{6}$ may also occur following both manual and ACD-CPR (Figure 2). Notably, among patients that fail to recover from cardiac arrest after CPR, fractures of the coronary arteries, often at multiple sites have been described. ${ }^{39}$ These injuries may also be associated with hemorrhage into the 
region of the bundle of $\mathrm{HIS}^{37,38,40}$ or the sinoatrial node ${ }^{37}$ further compromising cardiac conduction.

Differing injury patterns and incidence have begun to emerge when comparing types of CPR (i.e. standard, ACD, or standard followed by ACD). In our pooled analysis, the incidence of post-resuscitation rib fractures was $31.2 \%$, with a higher incidence noted for both suction cup based ACD-CPR devices and standard CPR followed by ACD-CPR compared to standard CPR alone (Table 3). $5-8,10,15,16,19-22,25,28,33,46,48-56$ Multiple rib fractures $(29.2 \%),{ }^{8}, 11,16,19,51,54$ bilateral fractures, ${ }^{54}$ and flail chest ${ }^{21,} 46,51,57$ occurred frequently as well. Although the overall pooled incidence of flail chest was $1.7 \%$, flail chest has been reported to occur at a rate of 5.6 per 100 survivors of CPR. ${ }^{57}$ Despite the common nature of these injuries, their detection is challenging. The majority of rib fractures $(86 \%)$ found during autopsies of patients after CPR were not detected with antero-posterior chest radiographs. ${ }^{58}$ Standard chest radiograph views with an additional oblique rib view, detected only $10 \%$ ( 8 of 83 ) of rib fractures found by chest wall ultrasound and after 3 weeks were positive in only 6 of 39 patients (15\%) who had fractures detected by repeat chest wall ultrasound.$^{59}$ Other common chest wall injuries include separation of costochondral junction $(0.5 \%),{ }^{8}$ clavicle fracture $(0.3 \%),{ }^{8}$ lung herniation, ${ }^{50}, 60,61$ mediastinal $(10.2 \%)^{5,6,8,28,51}$ or subcostal bleeding (17.6\%), ${ }^{62}$ and hemothorax. ${ }^{19,} 20,22,50,51,56$

Despite a pooled incidence of $15.1 \%$, sternal fractures are also commonly missed on plain chest radiographs. In one study, 33\% of the sternal fractures found at autopsy were not detected with antero-posterior chest radiographs. ${ }^{58}$ This suggests that the detection of sternal fractures in survivors of CPR may be even higher given the limitations of portable chest radiograph. The highest incidence of sternal fractures has been reported with ACD-CPR devices utilizing suction-cup based technology (80.6\%). ${ }^{10,63}$ ACD-CPR using piston-based devices has been associated with significantly more sternal fractures $(28.9 \%)$ than standard $\mathrm{CPR}^{10,11,54}$ and may have a higher incidence in women. ${ }^{64,65}$ The rate of thoracic complications (i.e. sternal and rib fractures) may be less with ACD-CPR utilizing loaddistributing band technology compared to standard CPR ( $45 \%$ vs. $14 \%$ respectively). However, the latter has been associated with an increase in vertebral fractures ( $0 \%$ vs. $4.5 \%)^{66}$

\section{PULMONARY}

The most commonly clinically recognized pulmonary complications (Table 4) associated with CPR include aspiration of gastric contents (10.9\%), pneumothorax (2.5\%), pneumomediastinum (1.4\%), pleural effusion / hemothorax (2.1\%), pulmonary laceration, and pulmonary contusion or hemorrhage (1.2\%). $5,6,8,10,11,16,18-20,33,55$ A common yet often unrecognized complication is pulmonary bone marrow or fat emboli which has a pooled incidence of $19.2 \%$ in autopsy series of CPR non-survivors. $5,7,16,19,21,28,46,63$ The clinical significance of this type of injury as well as the incidence amongst CPR survivors has not been clearly described. 


\section{THROMBOLYSIS}

Systemic thrombolysis may be indicated for a number of clinical conditions including myocardial infarction (MI), pulmonary embolism (PE), and cerebrovascular accident (CVA). ${ }^{67-69}$ Cardiac rupture has been described after both systemic thrombolysis administration for myocardial infarction ${ }^{70-72}$ and following percutaneous coronary intervention (PCI) with intracoronary thrombolysis. ${ }^{71}$ The relationship of the development of cardiac rupture to the presence of the underlying infarct and to the effects of systemic thrombolysis however remains controversial. ${ }^{73-75}$

Hemopericardium with cardiac tamponade may occur in the setting of systemic thrombolysis for MI and may be associated with either cardiac rupture, ${ }^{72,} 76 \mathrm{PCI}$-associated coronary artery injury, ${ }^{77}$ or may develop in the absence of either of these conditions. ${ }^{78-89}$ In the setting of MI, hemodynamic instability may not always improve following pericardiocentesis due to difficulty in aspirating thrombus, and thoracotomy may be unavoidable ${ }^{80,85,88,89}$ In one study of 43 patients, no increase in bleeding complications was observed in patients given thrombolysis during CPR. ${ }^{90}$

Thrombolytic therapy may also be used to treat acute massive pulmonary embolism (PE) manifested by hemodynamic instability or right ventricular failure. ${ }^{68,91} \mathrm{In}$ an analysis of 66 patients with cardiac arrest due to massive PE, no significant difference in major bleeding events was observed ${ }^{92}$ and CPR duration greater than 10 minutes did not increase the incidence of major bleeding complications. ${ }^{92}$ In our literature review, we found only 1 case of hemopericardium with cardiac tamponade after systemic thrombolytic (streptokinase) administration to treat $\mathrm{PE},{ }^{93}$ and no reports of cardiac rupture following thrombolytic administration for PE were identified.

\section{BEDSIDE ULTRASOUND DURING RESUSCIATION}

The traumatic complications of CPR are well known but typically difficult to assess in real time. Ultrasound is a readily available non-invasive assessment tool that may be utilized to further assess the patients' clinical status and potentially identify CPR-associated complications, thereby allowing prompt recognition and intervention without interrupting the resuscitation or transporting the patient. ${ }^{94,95}$ In one prospective analysis of 21 emergency department patients who underwent focused ultrasound assessment following CPR, 29\% were noted to have findings that could have resulted from CPR associated injuries. ${ }^{96}$ Similarly, inpatient assessment of cardiac ultrasound during inhospital arrest with CPR has been reported to be both feasible and prognostic in identifying potentially reversible causes of cardiac arrest. ${ }^{97}$

\section{CONCLUSION}

The incidence of reported CPR-associated cardiovascular and thoracic wall injuries varies widely. This may reflect several factors including the quality of the chest compressions and $\mathrm{CPR}$, the diligence in defining these complications in survivors and non-survivors and the varying sensitivity of different diagnostic modalities to detect these injuries. Patients who undergo CPR with circulatory adjuncts using automated or active compression- 
decompression devices have a higher reported incidence of cardiothoracic injuries. Bedside ultrasound may be a useful adjunct to assess and risk-stratify patients requiring CPR and to identify serious or life-threatening CPR-associated injuries.

\section{Supplementary Material}

Refer to Web version on PubMed Central for supplementary material.

\section{Acknowledgments}

We thank Lydia Kubiak for her artistry in drawing figure 2 for this manuscript. Additionally, we thank Judith Welsh for her assistance and expertise with the literature search and search strategies.

This work was supported by the Intramural Research Program of the Clinical Center and the National Cancer Institute of the National Institutes of Health.

\section{REFERENCES}

1. Koster RW, Baubin MA, Bossaert LL, et al. European Resuscitation Council Guidelines for Resuscitation 2010 Section 2. Adult basic life support and use of automated external defibrillators. Resuscitation. 2010; 81:1277-1292. [PubMed: 20956051]

2. Sayre MR, Koster RW, Botha M, et al. Part 5: Adult basic life support: 2010 International Consensus on Cardiopulmonary Resuscitation and Emergency Cardiovascular Care Science With Treatment Recommendations. Circulation. 2010; 122:S298-S324. [PubMed: 20956253]

3. Deakin CD, Nolan JP, Soar J, et al. European Resuscitation Council Guidelines for Resuscitation 2010 Section 4. Adult advanced life support. Resuscitation. 2010; 81:1305-1352. [PubMed: 20956049]

4. Shuster M, Lim SH, Deakin CD, et al. Part 7: CPR techniques and devices: 2010 International Consensus on Cardiopulmonary Resuscitation and Emergency Cardiovascular Care Science With Treatment Recommendations. Circulation. 2010; 122:S338-S344. [PubMed: 20956255]

5. Powner DJ, Holcombe PA, Mello LA. Cardiopulmonary resuscitation-related injuries. Crit Care Med. 1984; 12:54-55. [PubMed: 6690207]

6. Krischer JP, Fine EG, Davis JH, Nagel EL. Complications of cardiac resuscitation. Chest. 1987; 92:287-291. [PubMed: 3608599]

7. Bynum WR, Connell RM, Hawk WA. Causes of Death after External Cardiac Massage: Analysis of Observations of Fifty Consecutive Autopsies. Cleve Clin Q. 1963; 30:147-151. [PubMed: 14047647]

8. Patterson RH, Burns WA, Jannotta FS. Complications of external cardiac resuscitation: a retrospective review and survey of the literature. Med Ann Dist Columbia. 1974; 43:389-394. [PubMed: 4604258]

9. Bush CM, Jones JS, Cohle SD, Johnson H. Pediatric injuries from cardiopulmonary resuscitation. Ann Emerg Med. 1996; 28:40-44. [PubMed: 8669737]

10. Rabl W, Baubin M, Broinger G, Scheithauer R. Serious complications from active compressiondecompression cardiopulmonary resuscitation. Int J Legal Med. 1996; 109:84-89. [PubMed: 8912053]

11. Smekal D, Johansson J, Huzevka T, Rubertsson S. No difference in autopsy detected injuries in cardiac arrest patients treated with manual chest compressions compared with mechanical compressions with the LUCAS device--a pilot study. Resuscitation. 2009; 80:1104-1107. [PubMed: 19595496]

12. Fosse E, Lindberg H. Left ventricular rupture following external chest compression. Acta Anaesthesiol Scand. 1996; 40:502-504. [PubMed: 8738698]

13. Baldwin JJ, Edwards JE. Clinical conference: Rupture of right ventricle complicating closed chest cardiac massage. Circulation. 1976; 53:562-564. [PubMed: 1248089] 
14. Agdal N, Jorgensen TG. Penetrating laceration of the pericardium and myocardium and myocardial rupture following closed-chest cardiac massage. Acta Med Scand. 1973; 194:477-479. [PubMed: 4757227]

15. Machii M, Inaba H, Nakae H, Suzuki I, Tanaka H. Cardiac rupture by penetration of fractured sternum: a rare complication of cardiopulmonary resuscitation. Resuscitation. 2000; 43:151-153. [PubMed: 10694176]

16. Himmelhoch SR, Dekker A, Gazzaniga AB, Like AA. Closed-Chest Cardiac Resuscitation. A Prospective Clinical and Pathological Study. N Engl J Med. 1964; 270:118-122. [PubMed: 14067008]

17. Klintschar M, Darok M, Radner H. Massive injury to the heart after attempted active compressiondecompression cardiopulmonary resuscitation. Int J Legal Med. 1998; 111:93-96. [PubMed: 9541859]

18. Nagel EL, Fine EG, Krischer JP, Davis JH. Complications of CPR. Crit Care Med. 1981; 9:424. [PubMed: 7214982]

19. Baringer JR, Salzman EW, Jones WA, Friedlich AL. External cardiac massage. N Engl J Med. 1961; 265:62-65. [PubMed: 13686994]

20. Saphir R. External cardiac massage. Prospective analysis of 123 cases and review of the literature. Medicine (Baltimore). 1968; 47:73-87. [PubMed: 4866143]

21. Kaplan BM, Knott AP Jr. Closed-Chest Cardiac Massage for Circulatory Arrest. Effectiveness in 100 Consecutive Cases. Arch Intern Med. 1964; 114:5-12. [PubMed: 14152131]

22. Lawrence RM, Haley EM, Gillies AJ. Closed-Chest Cardiopulmonary Resuscitation: Results and Criteria for Application. N Y State J Med. 1964; 64:2523-2532. [PubMed: 14221320]

23. Reardon MJ, Gross DM, Vallone AM, Weiland AP, Walker WE. Atrial rupture in a child from cardiac massage by his parent. Ann Thorac Surg. 1987; 43:557-558. [PubMed: 3579415]

24. Biggart JD, McClure J. Right atrial laceration. Complication of external cardiac massage. Br Heart J. 1975; 37:652-655. [PubMed: 1148065]

25. Noffsinger AE, Blisard KS, Balko MG. Cardiac laceration and pericardial tamponade due to cardiopulmonary resuscitation after myocardial infarction. J Forensic Sci. 1991; 36:1760-1764. [PubMed: 1770344]

26. Hachiro Y, Okada H, Hayakawa T, Matsubara I, Maekawa K, Tanaka T. Cardiac tamponade secondary to cardiopulmonary resuscitation in a patient receiving antiplatelet therapy. Am J Emerg Med. 2000; 18:836-837. [PubMed: 11103742]

27. Reiter T, Ritter O, Beer M, Petritsch B. An unusual finding after resuscitation: contusio cordis. Clin Res Cardiol. 2012; 101:767-770. [PubMed: 22476822]

28. Bedell SE, Fulton EJ. Unexpected findings and complications at autopsy after cardiopulmonaryresuscitation (CPR). Arch Intern Med. 1986; 146:1725-1728. [PubMed: 3753112]

29. Charaschaisri W, Jongprasartsuk K, Rungruanghiranya S, Kaufman L. Forensic aspect of cause of subendocardial hemorrhage in cardiopulmonary resuscitation cases: chest compression or adrenaline. Am J Forensic Med Pathol. 2011; 32:58-60. [PubMed: 20706111]

30. Mayer C, Frank C, Frank D, et al. Left atrial wall dissection, mitral valve prosthesis dehiscence and pericardial hematoma: complex findings after successful cardiac resuscitation. Clin Res Cardiol. 2010; 99:57-58. [PubMed: 19882297]

31. Reinecke P, Notnagel C, Jehle J, Hort W. Circular hemorrhagic subendocardial necrosis after heart arrest and resuscitation. Z Kardiol. 2001; 90:437-441. [PubMed: 11486579]

32. Bodily K, Fischer RP. Aortic rupture and right ventricular rupture induced by closed chest cardiac massage. Minn Med. 1979; 62:225-227. [PubMed: 440243]

33. Sokolove PE, Willis-Shore J, Panacek EA. Exsanguination due to right ventricular rupture during closed-chest cardiopulmonary resuscitation. J Emerg Med. 2002; 23:161-164. [PubMed: 12359284]

34. Kempen PM, Allgood R. Right ventricular rupture during closed-chest cardiopulmonary resuscitation after pneumonectomy with pericardiotomy: a case report. Crit Care Med. 1999; 27:1378-1379. [PubMed: 10446834]

35. Milstoc M, Berger AR. Intracavitary cardiac thromboembolism: a complication of external cardiac massage. Chest. 1972; 62:645-646. [PubMed: 5082048] 
36. Gerry JL, Hutchins GM, Bulkley BH. Rupture of papillary-muscle of triscupid valve complication of cardiopulmonary resuscitation and a rare cause of tricuspid insufficiency. Am J Cardiol. 1977; 40:825-828. [PubMed: 920621]

37. Nishida N, Chiba T, Ohtani M, Ikeda N, Katayama Y, Yoshioka N. Relationship between cardiopulmonary resuscitation and injuries of the cardiac conduction system: Pathological features and pathogenesis of such injuries. Crit Care Med. 2006; 34:363-367. [PubMed: 16424715]

38. Frink RJ, Rose AP. Cardiopulmonary resuscitation and direct cardiac injury: Evidence of fractured coronary arteries and His Bundle hemorrhage. J Invasive Cardiol. 1997; 9:578-585. [PubMed: 10762964]

39. Frink RJ. A crush on the heart with CPR. J Invasive Cardiol. 2000; 12:A20. [PubMed: 10905825]

40. Kurkciyan I, Meron G, Sterz F, et al. Major bleeding complications after cardiopulmonary resuscitation: impact of thrombolytic treatment. J Intern Med. 2003; 253:128-135. [PubMed: 12542552]

41. Baker PB, Keyhani-Rofagha S, Graham RL, Sharma HM. Dissecting hematoma (aneurysm) of coronary arteries. Am J Med. 1986; 80:317-319. [PubMed: 3946450]

42. Wiemer M, Horstkotte D, Schultheiss HP. Non-surgical management of a perforated left anterior descending coronary artery following cardiopulmonary resuscitation. Z Kardiol. 1999; 88:675680. [PubMed: 10525930]

43. Mirrow N, Minami K, Vogt J, Korfer R. Rupture of gastroepiploic-coronary bypass graft due to cardiopulmonary resuscitation. J Cardiovasc Surg (Torino). 1994; 35:177-178.

44. Dorsa FB, Tunick PA, Culliford A, Kronzon I. Pseudoaneurysm of the thoracic aorta due to cardiopulmonary resuscitation: diagnosis by transesophageal echocardiography. Am Heart J. 1992; 123:1398-1400. [PubMed: 1575166]

45. Oren-Grinberg A, Shahul S, Sarge T. Dissection of the thoracic aorta following cardiopulmonary resuscitation. Crit Ultrasound J. 2011; 3:25-27.

46. Bjork RJ, Snyder BD, Campion BC, Loewenson RB. Medical complications of cardiopulmonary arrest. Arch Intern Med. 1982; 142:500-503. [PubMed: 6978115]

47. Englund E, Kongstad PC. Active compression-decompression CPR necessitates follow-up post mortem. Resuscitation. 2006; 68:161-162. [PubMed: 16297523]

48. Kottachchi DT, Dong J, Reid S. A rare complication of cardiopulmonary resuscitation. Can J Surg. 2009; 52:E1-E2. [PubMed: 19234634]

49. Hotta Y, Koizumi T, Kawanami J, Sakamoto A, Komiyama N, Nishimura S. Sternum fracture and haemorrhage after cardiopulmonary resuscitation. Resuscitation. 2007; 74:401-402. [PubMed: 17521796]

50. Emberger JS Jr, Racine L, Maheshwari V. Lung hernia associated with hemothorax following cardiopulmonary resuscitation. Respir Care. 2011; 56:1037-1039. [PubMed: 21740728]

51. Kloss T, Puschel K, Wischhusen F, Welk I, Roewer N, Jungck E. Resuscitation injuries. Anasth Intensivther Notfallmed. 1983; 18:199-203. [PubMed: 6638422]

52. Saternus KS. Direct and indirect trauma in resuscitation (author's trans1). Z Rechtsmed. 1981; 86:161-174. [PubMed: 7234133]

53. Black CJ, Busuttil A, Robertson C. Chest wall injuries following cardiopulmonary resuscitation. Resuscitation. 2004; 63:339-343. [PubMed: 15582770]

54. Kim EY, Yang HJ, Sung YM, et al. Multidetector CT findings of skeletal chest injuries secondary to cardiopulmonary resuscitation. Resuscitation. 2011; 82:1285-1288. [PubMed: 21705131]

55. Ayers WR, Doyle JT. Cardiopulmonary Resuscitation. Review of One Year's Experience in a General Hospital. N Y State J Med. 1964; 64:1929-1932. [PubMed: 14180875]

56. Minuck M. Organization and experiences of a cardiac resuscitation service. Can Anaesth Soc J. 1966; 13:52-61. [PubMed: 5916351]

57. Enarson DA, Didier EP, Gracey DR. Flail chest as a complication of cardiopulmonary resuscitation. Heart \& Lung. 1977; 6:1020-1022. [PubMed: 244316]

58. Lederer W, Mair D, Rabl W, Baubin M. Frequency of rib and sternum fractures associated with out-of-hospital cardiopulmonary resuscitation is underestimated by conventional chest X-ray. Resuscitation. 2004; 60:157-162. [PubMed: 15036733] 
59. Griffith JF, Rainer TH, Ching AS, Law KL, Cocks RA, Metreweli C. Sonography compared with radiography in revealing acute rib fracture. AJR Am J Roentgenol. 1999; 173:1603-1609. [PubMed: 10584808]

60. Batra AK. Lung herniation after CPR. Crit Care Med. 1986; 14:595-596. [PubMed: 3709206]

61. Sprague LD, Ferrigni FJ. Images in clinical medicine. Lung herniation after cardiopulmonary resuscitation. N Engl J Med. 2004; 351:695. [PubMed: 15306671]

62. Boz B, Erdur B, Acar K, Ergin A, Turkcuer I, Ergin N. Frequency of skeletal chest injuries associated with cardiopulmonary resuscitation: forensic autopsy. Ulus Travma Acil Cerrahi Derg. 2008; 14:216-220. [PubMed: 18781418]

63. Baubin M, Sumann G, Rabl W, Eibl G, Wenzel V, Mair P. Increased frequency of thorax injuries with ACD-CPR. Resuscitation. 1999; 41:33-38. [PubMed: 10459590]

64. Baubin M, Rabl W, Pfeiffer KP, Benzer A, Gilly H. Chest injuries after active compressiondecompression cardiopulmonary resuscitation (ACD-CPR) in cadavers. Resuscitation. 1999; 43:915. [PubMed: 10636312]

65. Rabl W, Baubin M, Haid C, Pfeiffer KP, Scheithauer R. Review of active compressiondecompression cardiopulmonary resuscitation (ACD-CPR) - Analysis of iatrogenic complications and their biomechanical explanation. Forensic Sci Int. 1997; 89:175-183. [PubMed: 9363626]

66. Pinto DC, Haden-Pinneri K, Love JC. Manual and Automated Cardiopulmonary Resuscitation (CPR): A Comparison of Associated Injury Patterns. J Forensic Sci. 2013

67. O'Gara PT, Kushner FG, Ascheim DD, et al. 2013 ACCF/AHA guideline for the management of ST-elevation myocardial infarction: a report of the American College of Cardiology Foundation/ American Heart Association Task Force on Practice Guidelines. Circulation. 2013; 127:e362e425. [PubMed: 23247304]

68. Jaff MR, McMurtry MS, Archer SL, et al. Management of massive and submassive pulmonary embolism, iliofemoral deep vein thrombosis, and chronic thromboembolic pulmonary hypertension: a scientific statement from the American Heart Association. Circulation. 2011; 123:1788-1830. [PubMed: 21422387]

69. Jauch EC, Saver JL, Adams HP Jr, et al. Guidelines for the early management of patients with acute ischemic stroke: a guideline for healthcare professionals from the American Heart Association/American Stroke Association. Stroke. 2013; 44:870-947. [PubMed: 23370205]

70. Park WM, Connery CP, Hochman JS, Tilson MD, Anagnostopoulos CE. Successful repair of myocardial free wall rupture after thrombolytic therapy for acute infarction. Ann Thorac Surg. 2000; 70:1345-1349. [PubMed: 11081896]

71. Arao K, Yasu T, Sugawara Y, et al. A case of oozing rupture after acute myocardial infarction with a maximal serum CK level of 1200. Kokyu to Junkan. 2006; 54:89-92.

72. Mobilia G, Masaro G, Neri GF, Alitto F. Hemopericardium caused by cardiac perforation during anticoagulation therapy. Description of 2 cases. G Ital Cardiol. 1991; 21:557-561. [PubMed: 1936760]

73. Becker RC, Charlesworth A, Wilcox RG, et al. Cardiac rupture associated with thrombolytic therapy: Impact of time to treatment in the late assessment of thrombolytic efficacy (LATE) study. J Am Coll Cardiol. 1995; 25:1063-1068. [PubMed: 7897117]

74. Oskoui R, Van Voorhees LB, DiBianco R, Kiernan JM, Lee F, Lindsay J Jr. Timing of ventricular septal rupture after acute myocardial infarction and its relation to thrombolytic therapy. Am $\mathrm{J}$ Cardiol. 1996; 78:953-955. [PubMed: 8888675]

75. Becker RC, Gore JM, Lambrew C, et al. A composite view of cardiac rupture in the United States National Registry of Myocardial Infarction. J Am Coll Cardiol. 1996; 27:1321-1326. [PubMed: 8626938]

76. Dhand A, Nakagawa K, Nagpal S, et al. Cardiac rupture after intravenous t-PA administration in acute ischemic stroke. Neurocrit Care. 2010; 13:261-262. [PubMed: 20697837]

77. Mixon TA, Tak T, Lawrence ME. Cardiac tamponade complicating myocardial infarction in the era of thrombolytics and platelet IIb/IIIa: case report and literature review. Am J Geriatr Cardiol. 2001; 10:133-138. [PubMed: 11360837] 
78. Mohammad S, Austin SM. Hemopericardium with cardiac tamponade after intravenous thrombolysis for acute myocardial infarction. Clin Cardiol. 1996; 19:432-434. [PubMed: 8723606]

79. Renkin J, de Bruyne B, Benit E, Joris JM, Carlier M, Col J. Cardiac tamponade early after thrombolysis for acute myocardial infarction: a rare but not reported hemorrhagic complication. J Am Coll Cardiol. 1991; 17:280-285. [PubMed: 1898952]

80. Georges JL, Tabone X, Metzger JP, Tamisier D, Baubion N, Vacheron A. Tamponade without cardiac rupture after repetitive thrombolysis in acute myocardial infarction. Arch Mal Coeur Vaiss. 1992; 85:1343-1346. [PubMed: 1290398]

81. Shyu KS, Ma HM, Hwang JJ, Shieh YY, Kuan P, Lien WP. Cardiac tamponade following thrombolytic therapy for acute inferior wall myocardial infarction - A case report. Acta Cardiol Sin. 1992; 8:96-100.

82. Ferrari E, Leonetti J, Cerboni P, Blanc P, Baudouy M, Morand P. Tamponade complicating thrombolysis of clots in the right cardiac cavities following myocardial infarction. Presse Med. 1993; 22:314. [PubMed: 8502632]

83. Turi ZG, Goldberg S, Littlejohn JK, et al. Dose-related efficacy and bleeding complications of double-chain tissue plasminogen-activator in acute myocardial-infarction. Am J Cardiol. 1993; 71:1009-1014. [PubMed: 8475860]

84. Heymann TD, Culling W. Cardiac tamponade after thrombolysis. Postgrad Med J. 1994; 70:455456. [PubMed: 8029170]

85. Win HK, Duncan A, Brack MJ. Haemopericardium following thrombolysis for acute myocardial infarction. Int J Cardiol. 2000; 76:91-93. [PubMed: 11121601]

86. Barriales Alvarez V, Alvarez Tamargo JA, Garcia Aguado M, Moris de la Tassa C. Cardiac tamponade secondary to hemorrhagic pericarditis following thrombolysis for acute myocardial infarction. Med Clin (Barc). 2002; 119:679. [PubMed: 12453383]

87. Imperadore F, Spagnolli W, Martinelli L, et al. Cardiac tamponade mimicking ventricular rupture after thrombolysis for acute myocardial infarction. Minerva Cardioangiol. 2003; 51:417-418. [PubMed: 12900724]

88. Tsai CT, Hou JY, Chou YH, Tsai CH. Cardiac tamponade after thrombolysis for acute myocardial infarction: A case report for the rare hemorrhagic complication. J Int Med T. 2003; 14:135-139.

89. Fuchs S, Weiss AT, Elami A, Zahger D. Sudden hemorrhagic tamponade simulating subacute ventricular rupture after acute myocardial infarction [2]. Int J Cardiol. 1997; 60:219-220. [PubMed: 9226295]

90. Scholz KH, Tebbe U, Herrmann C, et al. Frequency of complications of cardiopulmonary resuscitation after thrombolysis during acute myocardial infarction. Am J Cardiol. 1992; 69:724728. [PubMed: 1546644]

91. Lankeit M, Konstantinides S. Mortality risk assessment and the role of thrombolysis in pulmonary embolism. Crit Care Clin. 2011; 27:953-967. vii-viii. [PubMed: 22082522]

92. Janata K, Holzer M, Kurkciyan I, et al. Major bleeding complications in cardiopulmonary resuscitation: the place of thrombolytic therapy in cardiac arrest due to massive pulmonary embolism. Resuscitation. 2003; 57:49-55. [PubMed: 12668299]

93. Giles PJ, D'Cruz IA, Killam HA. Tamponade due to hemopericardium after streptokinase therapy for pulmonary embolism. South Med J. 1988; 81:912-914. [PubMed: 3393951]

94. Bendinelli C, Easton R, Parr M. Focused assessment with sonography for trauma (FAST) after successful cardiopulmonary resuscitation. Resuscitation. 2012; 83:e17. [PubMed: 21958932]

95. d'Aranda E, Cotte J, Lacroix G, Monchal T, Meaudre E. Hemorrhagic shock after cardiopulmonary resuscitation, bedside ultrasonography interest. Ann Fr Anesth Reanim. 2013; 32:67-68. [PubMed: 23245485]

96. Corbett SW, Ocallaghan T. Detection of traumatic complications of cardiopulmonary resuscitation by ultrasound. Ann Emerg Med. 1997; 29:317-321. [PubMed: 9055769]

97. Varriale P, Maldonado JM. Echocardiographic observations during inhospital cardiopulmonary resuscitation. Crit Care Med. 1997; 25:1717-1720. [PubMed: 9377888] 


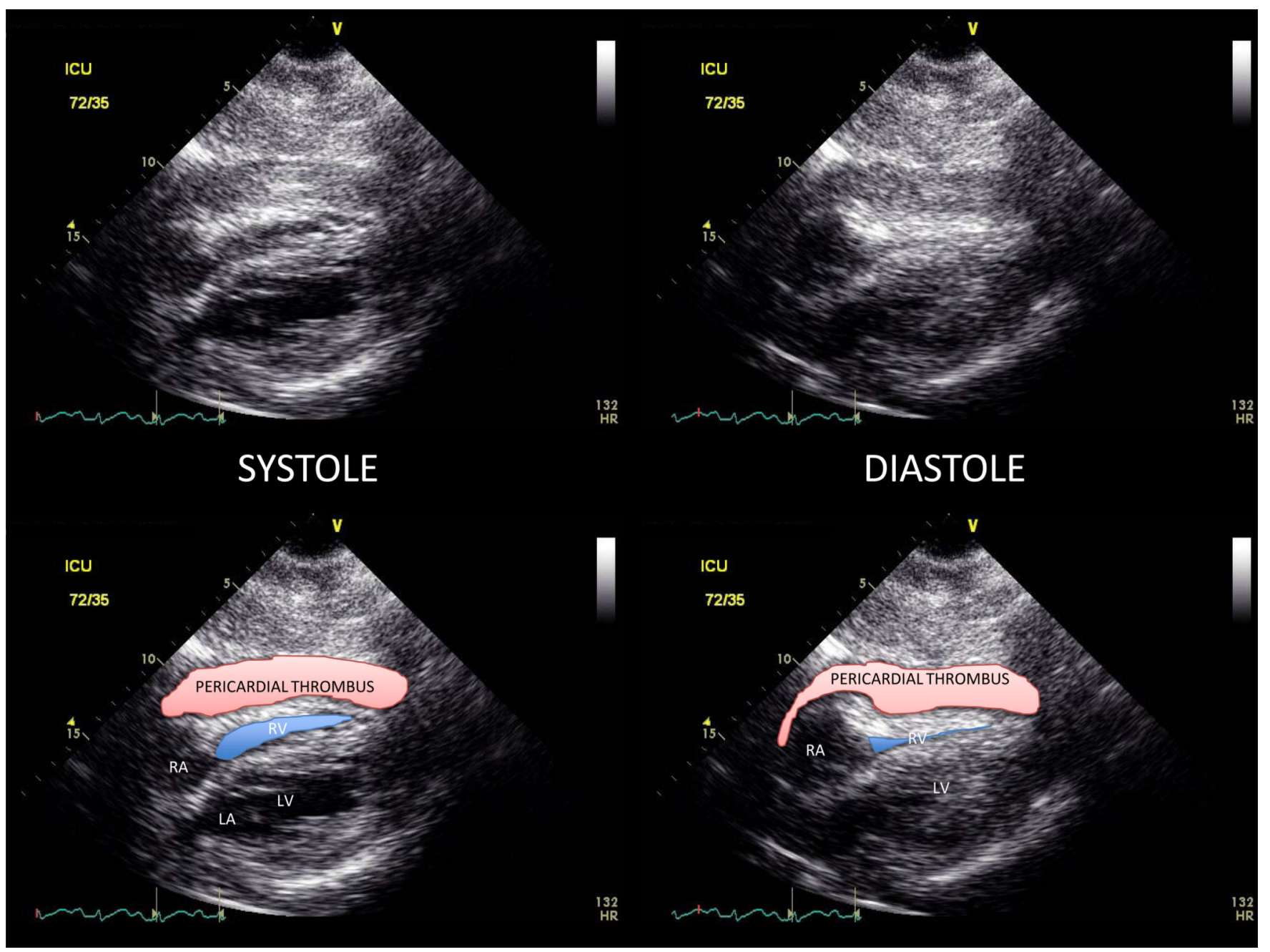

Figure 1.

Bedside transthoracic echocardiogram following initial resuscitation showing interval development of an echodense pericardial collection with collapse of the right ventricle during diastole. 

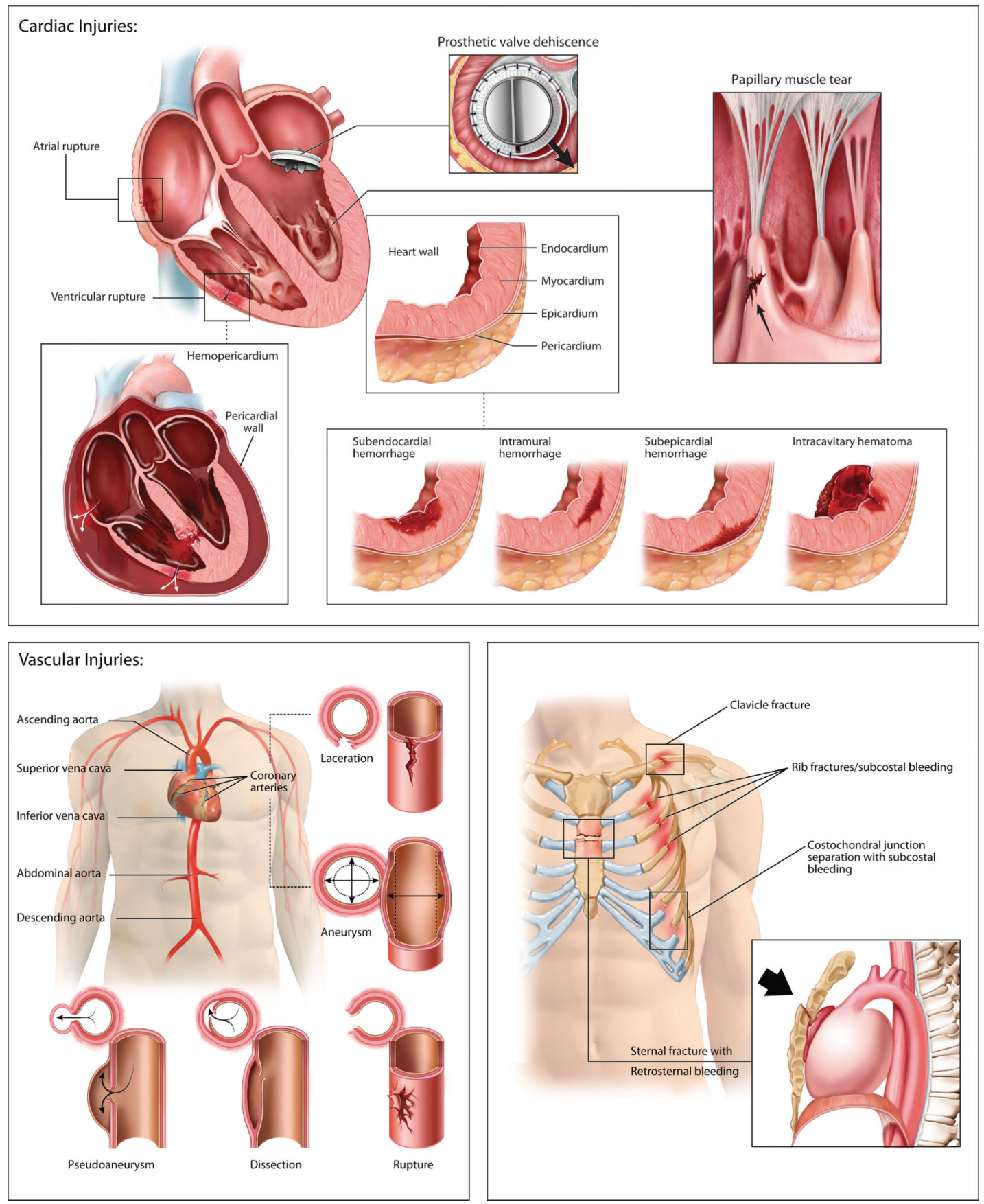

Figure 2.

Schematic of CPR-associated cardiac, vascular, and thoracic wall injuries. 


\begin{tabular}{|c|c|c|c|c|c|c|}
\hline 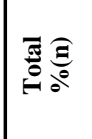 & $\mid \begin{array}{l}\hat{\bar{a}} \\
\frac{a}{0} \\
\hat{\alpha} \\
\infty\end{array}$ & 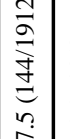 & $\begin{array}{l}\hat{0} \\
0 \\
0 \\
0 \\
0 \\
+ \\
+\end{array}$ & 3 & & | \\
\hline
\end{tabular}

\begin{tabular}{|l|l|l|l|l|l|l|l|}
\hline 롤슬 & 6 & 6 & & 6 & 6 & 6 & \\
\hline
\end{tabular}

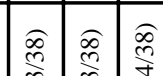

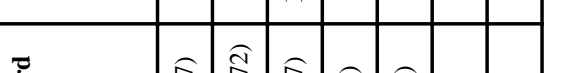

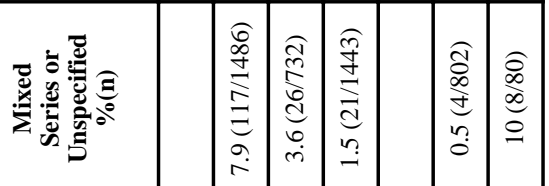




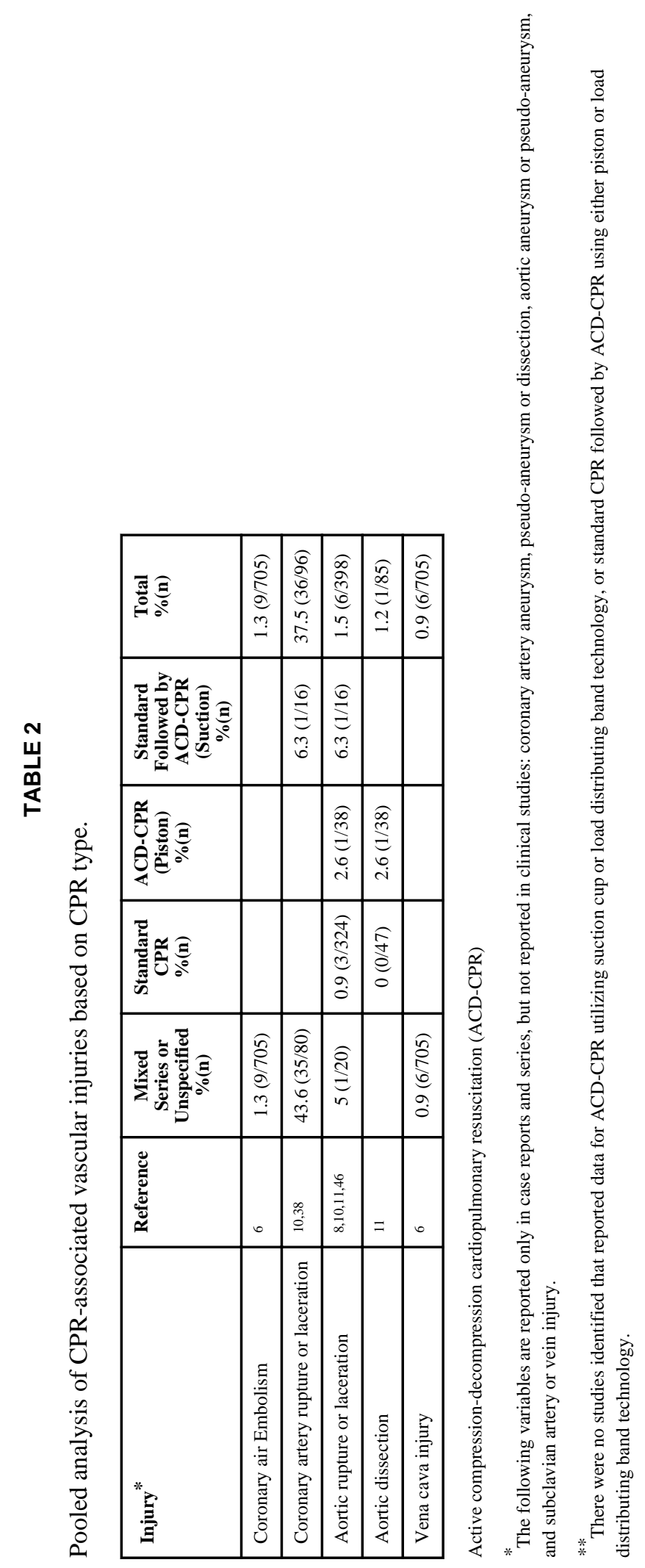




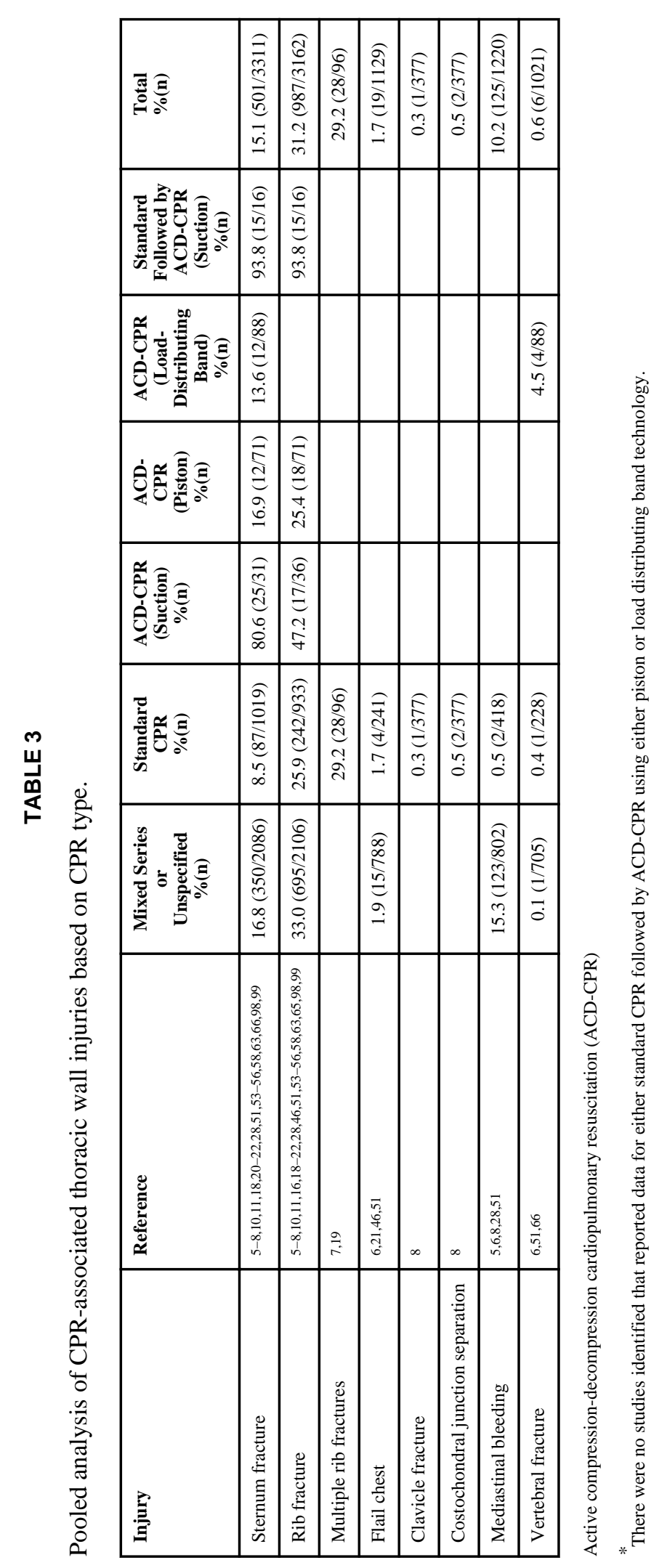




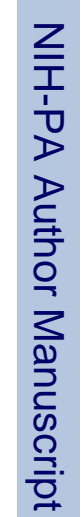

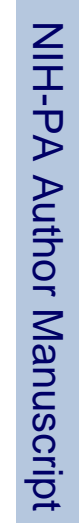

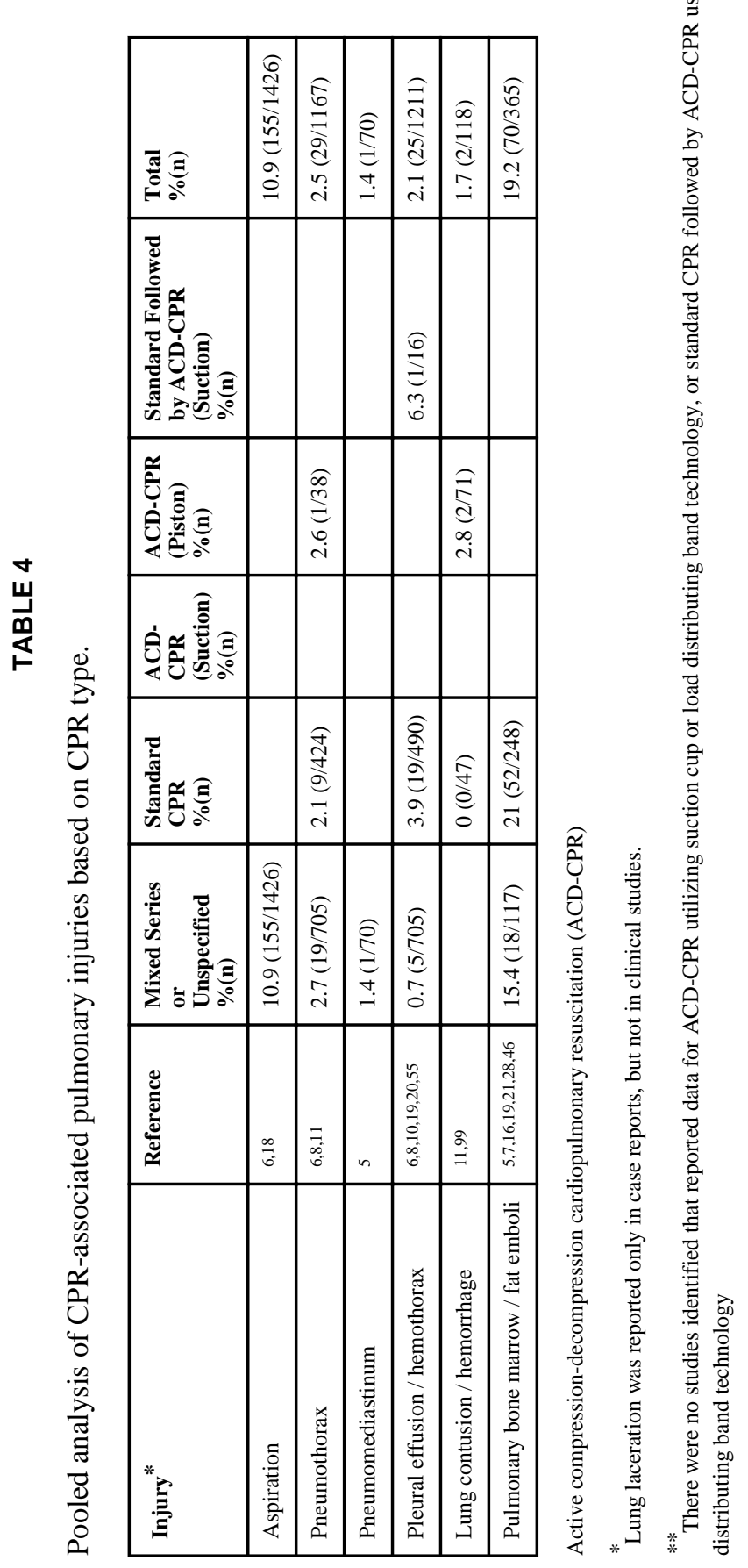

Resuscitation. Author manuscript; available in PMC 2015 June 01. 